\title{
Valuation Means of Students' Competences at the University
}

\author{
Marina Ivanovna Aldoshina ${ }^{1}$ \\ ${ }^{1}$ Federal state government-financed education institution of higher professional education, Orel State University, \\ Komsomklskaya St., 95, Orel Town, Russian Federation \\ Correspondence: Marina Ivanovna Aldoshina, Federal state government-financed education institution of \\ higher professional education, Orel State University, Komsomklskaya St., 95, Orel Town, 302026, Russian \\ Federation. E-mail: maraldo1@rambler.ru
}

\author{
Received: July 20, 2014 Accepted: August 15, 2014 Online Published: November 27, 2014 \\ doi:10.5539/ass.v10n24p77 \\ URL: http://dx.doi.org/10.5539/ass.v10n24p77
}

\begin{abstract}
This article is devoted to the pedagogical problems of educational progress and students' competences valuation in educational progress at the University. This problem has appeared because of transition on higher education standards of new generation. The aim of this article is a qualitative analysis of a variety of assessment tools, testing is the most effective of them in the educational process of the University. The author touches upon objective and subjective funds students' competences valuation means. In details the author characterizes score-rating (or module-rating) system, standardized tests with additional creative tasks, Case-study method, portfolio, developing cooperation method, Delphi method, business game, project method and etc.
\end{abstract}

Keywords: valuation means, the competence of students, academic achievement, score-rating system

\section{Introduction}

In the twenty-first century education is recognized as one of the leading mechanisms of a sustainable development of the society. The society of Informational Technologies is much more interested in the fact that its citizens are able to independently, be active, make decisions, and flexibly adapt to the changing situations of life. In the new conditions the most important feature of the modern education is its focus on preparing students for active mastering of the situation of social changes. Education is considered not as an end in itself, but as the main mechanism of changing in knowledge, values, behavior and lifestyle, and it should have a leading character. At the turn of the XX-XXI centuries, there is a transition to a new type of social and cultural inheritance. The old paradigm is based on the transfer of a set of activity patterns in the form of a logically completed system of knowledge and rules. A new-shifts the focus on the development of our own strategies in the unpredictable sociocultural situations. "Training" is based on the belief that knowledge and experience will protect the person in a problem situation spontaneously appeared in the future practice. Education consistent with the new paradigm, orientates the human toward openness for experience, at the anticipation of any possible problems. Consequently, the most strategic direction of the educational system development is in solving the problem of personality-centered learning, the kind of education in which the focus is on the individuality of the student.

It should be noted that the results of education can be the subject of dialogue, both within the system and between society and the state. Educational results, representing a decomposition of the goals of education, are inextricably linked to the conditions, in which the educational process is taking place, and the conditions reflect the abilities of the society in providing education. Definition of objectives not taking into account the conditions can lead to a sharp increase in the needs of the general education system of resources that cannot be met. Laying on the standards of education the mission of assuring its quality, you should understand that this puts well known restrictions on the sphere of its use and on the used recourses. On the one hand, the development of a standard based on the goals of education, "tied" to the current opportunities to support them, most likely will not achieve the desired at the present stage new quality of education. On the other hand, guarantees cannot be unlimited and require a reasonable restriction. With regard to the educational standards, this means the need to introduce the concept of "minimal but sufficient level of education," which outline the range of the minimum necessary resources, and the state must guarantee to provide them.

With the transition to high school education according to federal state educational standards we notice a reorientation to the competence approach. Within the framework of the competency approach the effectiveness 
of educational process at the University is not considered through the familiar, traditional set of knowledge, ways of life, qualities and characteristics of a specialist, but through the formed competences. This requires a change in the system of assessment of the academic achievements of the students at the university. The problems is not only the need to change the assessment methods, but also a change in the measurement procedures; the presence of standards, patterns of activity, which can be associated with the result; leveling of the subjective factor in the evaluation; The present ability of educational achievements of the students in a bright, accessible and as effective as possible form, etc.

The term "competence" has been introduced in the scientific apparatus in USA in 60-70 years of the XX century. $\mathrm{N}$. Chomsky in the theory and practice of teaching foreign languages studied various types of linguistic competence. The concept "competence" has been developed and introduced by the American linguist D. Hymes. In the domestic psycho-pedagogical literature, the concept "competency" and "competence" have spread in 80-90 years of XX century due to the emergence of competence-based approach in the methodology of education. The results of the analysis of the scientific literature show that at this stage of development of professional pedagogic, the concepts "competence", "competency" are interpreted ambiguously. The questions of using competence-based approach are widely discussed in the press, the researchers identified the content and essence of the concepts "competence", "competency", "professional competency", the structure and kinds of competency are being analyzed. The analysis of theoretical sources revealed that there are different approaches to the content of the concept "competence": as a specific person's ability to solve complex social and professional problems, providing a high-quality productive activity and a set of personality's qualities (knowledge, skills, ways of activity) which are needed to perform a certain group of actions in the field of a particular kind of activity. Thus, the essence of competence manifested in the implementation of the various activities, in the above definitions, our attention is focused on the diverse nature of this concept (M. V. Voronov, D. P. Zavodchilov, E. F. Zeer, I. A. Zimnyaya, D. A. Ivanov, V. E. Medvedev, G. I. Pismensky, V. A. Slastenin, A. I. Subetto, Y. G. Tatur, A. V. Hutorskoy) (Voronov, 2009; Druzhilov, 2001; Zimnyaya, 2004; Paszkiewicz, 2011; Radionova, 2004). Some researchers emphasize the importance of personal qualities, while others-the methods of action, providing an effective solution to real problems in a particular field of activity. Most researchers understand competence as a set of inter-related personality's qualities (knowledge, skills, abilities, values, relationships, ways of activity), set for a particular range of subjects and processes, necessary for a successful activity in a particular social or professional field.

\section{Method}

Today, there is no single technology of evaluating the formed competencies of students in the learning process. Competences characterize different kinds of skills and the ability to achieve results in specific situations of personal and professional growth. Competences must be specified concerning the results of learning process in certain subjects. In this case, the job of the teacher will be the correlation of teaching methods and evaluation procedures. The main purpose of teacher's evaluation of the results of learning process, the level of formation of students' competences is the development of their cognitive activity and motivation to study the subject and the mastering of professional sphere.

To determine the competences' formation it is necessary to use a certain fund of assessment tools. The modern system of evaluation of the results of the learning process, correlates with the concept of a mark, allows you to select a number of serious aspects that require attention:

- the orientation of the estimation is preferably on an external control, followed by sanctions, but not on the motivation to improve the results;

- preferential orientation of control and evaluation tools to check the reproductive level of mastering, to check only factual and algorithmic knowledge and skills; lack of a systematic approach to the creation of packages of effective meters, intended for authentic assessment (assessment of their selves) of educational achievements, a balanced assessment of educational achievements, the evaluation of students activity, the evaluation of a range of works for a certain period;

- the lack of general evaluation criteria in teachers, as well as standardized meters and a single scales, causing incomparability of students' assessments, and of the results achieved by individual educational institutions; a lack of an effective independent system of certification of high school graduates;

- a weak material and technical basis of the assessment system at the university, the lack of monitoring tools, control and training programs, mathematical and statistical packages for processing the control results and computer classes with network equipment. 
This involves the use of various objective and subjective evaluation procedures. Objective tests with a choice of response (actions) of the proposed options. The subjects' answers are process using a key. Tests, questionnaires for the diagnosis of personality traits of future professionals. The method of "subjective scaling and self-competence assessment", when an expert has to interpret the subject's answers to the test, who on his turn evaluates some objects and concepts on the degree of similarity or on the degree of subjective preference in the professional sphere. Subjective methods for assessing competencies are presented by expert evaluation methods; they include observation, content analysis, interviews, discussion, and analysis of the activity products, active playing diagnostic techniques and projective diagnostic techniques.

For the evaluation of the former professional competencies of students formed the most common are the following methods: In details the author characterizes score-rating (or module-rating) system, standardized tests with additional creative tasks, Case-study method, portfolio method, developing cooperation method, Delphi method, business game, project method and etc.

\section{Results}

Let us dwell on some of them, used for the evaluation of educational achievements and professional competencies of 1st year students of the Faculty of Pedagogy and Psychology, Orel State University, studying educational discipline "Multicultural Education" in the direction of preparation psycho-pedagogical education (degree-Bachelor).

The rating system is an effective method of evaluation of educational achievements and the formation of competences in the educational process. The rating system-a method in which learning material is divided into logically completed parts (modules), after learning each part there is an interim certification (frontier control) test, testing papers, colloquium. The work is evaluated in points. This system is suitable for the assessment of competences, since it is possible to evaluate in points not only knowledge and skills, but also creative possibilities: Activity, originality to solve a problem, the ability to organize work in a group. The maximum number of points-100. To activate the cognitive activities in the studied course, the student can get 50 points on the control, and 50-during lessons. The rating reflects the fullness of participation in lessons (3 points-has systematically been active, asking questions, answering frontal questions of the teacher, actively involved in cognitive activity during the lesson, 2 points-situational displayed activity; 1 point-attended the lessons, listened, watched, recorded by teacher's order, 0 points-was absent).

Each module includes compulsory activities: practical, seminars, independent creative tasks, additional tasks of your choice (essay, report, video presentation, game, case, etc.). The general formula for calculating the total score for each type of work can contain 4 factors: the initial "cost" of the type of work, quality of performance coefficient (valuation), difficulty coefficient and the coefficient of fulfillment date.

For example, we have developed a chart of report evaluation, which includes the following evaluation criteria (as the essential characteristics of formation of the relevant professional competencies): the completeness of coverage of the problem; quality of performance (literacy, information value, scientific content); the ability to answer questions (laconism, reasonableness, "submergence in the theme," awareness); appropriate use of visual aids. Technological chart of independent work takes into account the urgency of the implementation; the quality of the performance; completeness; comments of fellow students and the teacher

The advantage of the system is that the entire group of students knows when and by how many points every kind of activity is estimated. After studying the course, the student can independently determine his final grade. Another advantage is the cumulative result, which stimulates the student to constantly increase the luggage of educational achievements.

By teaching methods within the score-rating system, at the beginning of the study of the training course the teacher tells the students about the criteria of points distribution to the types of work, the reporting forms and the frequency of control measures.

The final grade is proportional to the part of all the tasks made, which takes into account the sum of all classroom as a percentage of the minimum possible number of points, the total number of points as a percentage of the maximum number of points on the chart of independent work, and the amount of points earned on the frontier and final control.

Standardized tests and tests with additional creative task are a widely used means of assessment. Standardized test-is a standardized task of the open form, where a number of established answers can be supplemented by their own without any restrictions. It significantly differs from the traditional assessment of learning outcomes, implemented using closed tasks that require one correct answer from a set of proposals. Test to check the 
competence does not evaluate the information, knowledge, but ways of working. Completing quests of the open type require from students to commit specific activities to find the required information, to solve a problem appeared or to arrange the results of its decision. Such a task always requires a detailed answer. The implementation of competence-based approach using standardized tests is the need for technological measures; measurement accuracy; the existence of the same rules for everybody; combination with other educational technologies.

Case-study method-designing elements of single and multiple cases. The essence of this method is that the training material is presented in the form of problems (cases), and competences appear as a result of active and creative work: independent implementation of goal-setting, collecting the necessary information, its' analysis from different perspectives, hypothesizing, drawing conclusions, self-control of the learning process and its outcomes (Khotinets, 2012, p. 140).

Learning Tools in case-technologies: programs of studying the subjects, guidelines for the implementation of tests, course and final qualifying works; publications: books, textbooks for each subject of the course; special printed educational and practical textbooks with texts for self-control: survey (installation) audio and video lectures for each subject of the course; questions for colloquia and workshops; computer electronic books and computer training programs on the disciplines of the course. The connection of case-technology with the modular construction of the course is an effective.

The structure of the case:

- The presentation of the theme, the formulation of the problem, issues, tasks;

- A detailed description of practical situations, related events, conditions, options, alternatives;

- Training and methodological support: visual, distributing or other illustrative material on paper, or electronic media; presentation of recommendations "How to deal with a case?"; an offer the used resources: literature, media, internet resources, etc.

- Determination of the operating mode;

- Evaluation of the work in stages.

The algorithm and operation mode within case-method includes the following steps:

1) Organizational part. Case delivery (5 min.);

2) Individual self-study work with the case (10 min.);

3) Checking the assimilation of theoretical material on the topic (10 min.);

4) Working in small groups (30 min.);

5) Discussion (15 min.);

6) Arranging the results of the work (5 min.);

7) Sizing up by the teacher ( $5 \mathrm{~min}$.).

As an example of the case-task we can present the following: «Anzhelika, 16 years old, 11-th year of studying, and comprehensive school in the province. The most of graduates go to universities or colleges, a little after school go to work. The girl's family emigrated from Transcaucasia in 1990. The family supports cultural and linguistic ties with the country of origin, but at the same time it makes efforts to integrate into the new community. The girl's parents-are middle class both support further education and allow her to spend her free time as her peers do. The girl is watchful of the prospect of entering the Faculty of Philology of the provincial university"

This method stimulates cognitive and creative activity of students, reducing the proportion of reproductive activity. To achieve this goal open learning is widely used (software, distance learning, internet learning packages, interactive videos); text and multimedia packages with a set of specific information, questions and tasks.

An interesting methodical finding is the use of «3-D» technology. The teacher schematically sketches the situation on a sheet of paper or a flip chart, and then asks the students to formulate the problem quickly, in one sentence. A correct statement of questions and the use of three-dimensional analysis technique, allows in a short time to single out three elements of the problem in three aspects (the names of the aspects are visually highlighted) situation (time mode, the lack of resources, geography); participants (dissatisfied customer, student, impatient boss, teacher, unreliable supplier, profitable partner); " $\boldsymbol{I}$ " (lack of competence, experience, conflict of 
values, motivation). Singling out the tridimensionality of the problem allows us to determine many activity options. Asking the students guiding questions, the teacher helps to verbalize the problems and the activity options depending on the purpose of the analysis.

Portfolio became one of the most common in Western countries methods for evaluating educational achievements and competencies. Portfolio (folders)-a method of collecting, storing and evaluating of student's fixed achievements in a certain period. Traditionally, there are several types of portfolio: business includes the student's work for a certain period of time, and demonstrate the changes in educational achievements, protocol in the documentary form reflects the results and achievements and confirms the student's self-dependence, process illustrates the academic achievements of the students at different stages of the learning process; concluding is used to obtain a total assessment of the student's competence (Zvonnikova, 2009, p. 28). In the course "Multicultural Education" concluding portfolio may include a portrait of the student; a comparative table "Modern approaches to understand multicultural education"; thesaurus of the discipline; a report on "The practice of multicultural education in the United States"; a table with independently developed criteria "Analysis of acculturative and dialog approaches of multicultural education"; schemes "Signs of ethnos and ethnicity"; a set of situational tasks of school, extracurricular, student, and leisure life; a research "Theories of ethnic identity of the individual" essay "Different sides of patriotism and tolerance"; introspection.

The portfolio on discipline consists of three parts and includes:

1) A portrait of the student (personal information: the date and place of birth, information on education, "My personal qualities."

2) The work carried out during the mastering of the discipline.

3) The introspection sheet (questionnaires, essays in the problem field: "I experienced the greatest difficulties while doing ...", "I believe that these difficulties were associated with ...", "I will be more successful if ..." etc.

For the selection of materials in the portfolio we offer, for example:

1) To select the three best works, made within the course;

2) To select the work of the beginning of course studying, of middle and the end of the course;

3) To select the best works that illustrate the developed skills and competencies;

4) To select one work of each type-essay, project, scientific article, a glossary, a review of the work of a fellow student, etc.

Modern information technologies allow a different kind of portfolio: multimedia (simultaneous use of different means of presentation of information and its processing in a single container object), internet resources (information, located in the computer network, and which is information object that exist in files, containing different types of information (text, graphics, video, audio, etc.).

The control of learning outcomes should be permanent, systematic and should carry out at all stages. Requirements for students should be necessary and sufficient to achieve the planned results-the formation of competences.

Project method-is a set of techniques that allow formulating and solving a problem with obligatory presentation (public presentation) of the results by independent actions of the students. Project-based learning is teaching independent and creative professional activity individually or in micro group. The project activity supposes the presence or stimulates the formation of the following projecting skills:

a) The ability to analyze data, to specify educational objectives.

b) The ability to select the learning material in accordance with the goals and objectives.

c) The ability to present the learning material in the form of patterns of students' activity.

d) The ability to correlate the presented activities model with the life experience of the students.

e) The ability to single out possible technological ways of learning and relate them to the didactic purpose, by methods, means and forms of learning organization, methodological features of the theme, educational opportunities of the students.

f) The ability to develop various kinds of procedures for learning and cognitive activity of the students during the process of their promotion to a higher level.

g) The ability to evaluate and compare the kinds of activity structure of the students, to choose one best option. 
h) the ability to develop motivational and personality-developing situations.

i) The ability to define the structure of the activities of the teacher in accordance with the structure of learning and cognitive activities of the students.

j) The ability to pick up visual aids, distributing books, as well as audio and video materials.

k) The ability to assess the ways of using of external conditions of the educational process.

1) The ability to make correction of the structure of the educational process.

m) The ability to manage time for each stage in the educational process.

n) The ability to set the project of the educational process in a document in a written or graphic form.

The project activity stimulates students' initiative, independence and critical thinking, creativity and business success, project learning makes the educational process in the university more active, entertaining and effective. We use different kinds of projects in the course "Multicultural education:

5) scientific projects:-Participation in research projects carried out by departments, laboratories, research institutes, by the whole university and other organizations (for example, "Matryoshka and Kokesi: general and special");-Participation in the grant (state budget and economic contracts) activity, including paperwork, application preparation, presenting the project at a competition, etc.

6) educational projects:-teaching students partitions of disciplines from the mastered training areas (for example, making a report on the experiences of multicultural education in Mali by the postgraduate U. Kulibali); -development and implementation of programs for different types of disciplines, types, training profiles, educational levels (for example, the development of the course "Principles of Tolerance" (10 the grade) for a profile humanitarian class;-development of programs for profile and elective courses in the mastered field (for example, a course "Traditional Russian rag doll in Russian ethnic culture" for the class with the in-depth study of the aesthetic disciplines).

7) creative projects:-publishing projects (periodicals, internet publication, network);-creative projects in the framework of Olympics, competitions, festivals, etc. An example is the projects that took place in the final round of regional intercollegiate competition of educational projects "Steps" in 2013-"Sources of Orlovshina", "History of the Shrine" ethno-camp, "Doll calendar of the Slavs" in 2014.

8) social projects:-monitoring of various aspects of personality and professional development of the students in the university (tolerance, professional competence in the various fields of activity);-projects related to the construction of a general cultural educational space in the region ("Christmas Angel", "Shrovetide celebrations");-popularization of scientific knowledge (healthy lifestyle, significant dates of relevance to the cultural space of the region, for example, the opening of the museum of toys of the Faculty of Pedagogy and Psychology, in Orlovsky Museum of Fine Arts).

9) service projects:-projects in the practical application of professional competencies in the direction of training (centers of education and support of persons with disabilities, educational help for the family, psychological consultations, (such as for children and the families of migrant workers), leisure centers).

10) presentation projects:-presentation of research results (of the mass media, multimedia technologies), development and author finds (on-line project, show projects, festivals, exhibitions, public-art);-development of PR-campaigns on scientific results popularization, projects of educational programs.

A widespread example of the activation of training activities in the students' group and a high quality procedure of mastering of educational achievements of students is the use of video presentations. PowerPoint presentations have the advantages of easy replication, modification, exchange and storage. Software products for creating presentations (professionals and inexperienced users) include Microsoft Power Point, Windows Movie Marker, Corel Presentation, Star Office Presentation, Macromedia Director, Demo Shield, Matchware Mediator and others. Presentation used in the classroom, depending on the degree of student's participation, can be divided into presentation-visualization (video presentation and (or) audio series) and interactive presentations (including the student in the process that improves the perception and assimilation of the material). There are requirements for video presentations: conciseness and brevity of the statement, a maximum information content of the text; consolidation of semantically related information elements in a holistically perceived groups; text highlights of pieces of information; simplicity of the sentences construction; organic addition of graphics to the text. 


\section{Discussion}

In accordance with the requirements of the standard to determine the correspondence of personal achievements of the students to the staged requirements of the educational process, there are foundations of assessment tools for ongoing monitoring of progress and interim certification. These funds include a variety of types for maximum approximation of the ongoing progress monitoring and the interim certification of the students to the conditions of their future professional activity. To this end, employers and teachers, teaching adjoining subjects are involved as external experts. The fund of assessment tools should be formed on the basis of the key principles of evaluation: validity: assessed objects should be relevant to the learning objectives; reliability: using uniform criteria and indicators for assessing the achievements; objectivity: to obtain objective and reliable results while making control with a variety of purposes. The main requirements for the assessment tools of competencies formation, are integrative; a problem-activity nature; actualization of professional activity in the quest content; a connection of the criteria with the planned results; expertise in the professional community. Some researchers and practitioners stress the importance of phasing and systematicness of intermediate and final evaluation of students' competences formation (Voronov, 2009; Ermakov, 2011; Novikov, 2004; Pashkevich, 2011; Slastenin, 2010, p. 10; General editor Ruegg, 1992; Hofstede, 1991; Pelikan, 1992), the diversity of the fund assessment tools (Druzhilov, 2001; Zvonnikova, 2009; Raven, 2002, p. 15; Locke, 2006), their applied orientation (Voronov, 2009; Zeer, 2006; Seryakova, 2005; Sidorenko, 2001; Subetto, 2007; Rothenberg, 1996).

\section{Conclusion}

The development and use of assessment tools fund of students' competencies in the educational process of the university is a topical issue of pedagogical theory and practice of university education. The formation of general and professional competencies of the students, as a result of the educational activities at the university, largely depends on the organization of the process of evaluation of educational achievements of students and the diversity of the used methods and techniques (Druzhilov, 2001, p. 58). Means of evaluating the competencies of the students are integral parts of training and methodological support of education system quality assessment and include different types of evaluating of current and boundary control of progress, intermediate and state (final) certification. A wide range of manifestation of control and assessment activities allows to significantly enhance the experience of its manifestations in various spheres of professional activity. We have tried to consider the variety of assessment tools of educational achievements and the formation of students' competences in the same field of study psychological pedagogical education, which does not limit the field of research. Continuing research is associated with the study of other methodological and methodical approaches of using various means of evaluation of educational achievements and students' competencies at the university, improving diagnostic procedures and expanding the range of competences, further development of laws and principles of effective formation in a multilevel system of vocational education. Thus, there is a change in the evaluation nature from one-time assessment, situational metering to complex, which characterizes the level of development of competencies of a professional.

\section{References}

Druzhilov, S. (2001). Effectiveness criteria of professionals in terms of joint activity. Joint Scientific Journal, 22, 44-45.

Ermakov, D. (2011). Competence-based approach in education. Pedagogy, 4, 11-13.

Hart, J. (2006). Interpreting cultures: Literature, religion and the human sciences. New York; Basingstoke Hants.

History of the University in Europe (Vol. 1). (1992). Oxford.

Hofstede, G. (1991). Culture's Consequences: International Differences in Work-related Values. Newbury Park est. Sage.

Khotinets, V. (2012). Methodological bases of ethnic and cross-cultural psychology. M: FORUM.

Novikov, D. (2003). Statistical methods in educational researches (typical cases). M: MZ-Press.

Pashkevych, A. (2011). The implementation of competence-based approach in education process undergraduate students. Siberian Education Journal, 5.

Pelikan, J. (1992). The idea of University (a Reexamination). New Haven and London.

Radionova, N. (2004). Competence approach in pedagogical education. News of Volgograd Pedagogical University, 1, 46. 
Raven, J. (2002). Competence in modern society. Identification, development and realization. M: Kogito Centre.

Rothenberg, J., \& Cassant, S. M. (n. d.). Teaching and learning in multicultural classrooms. The Educational Forum, 77-83.

Seryakova, S. (2005). Psycho-pedagogical competence of the teacher of additional education. Monograph. MSPU.

Sidorenko, O. (2001). The formation of professional-value orientations of first-year students during their training in pedagogical university. $\mathrm{PhD}$ thesis. $\mathrm{M}$.

Slastenin, V. (2011). Introduction to pedagogical axiology tutorial for higher school students. M.: Publishing Center "Academy".

Subetto, A. (2007). Competence-based approach. M.: Research Center of the quality of specialists' training.

Voronov, M. (2009). Competence-oriented approach as a system solving of the urgent problems of modern national education. The implementation of competence-based approach in the educational process: Proceedings of SGA. M.: SSU.

Zeer, E. (2006). Personality-develop professional education. Ekaterinburg: Publisher RGPPU.

Zimnyayar, I. (2004). Key competences as effective-targeted base of competency-based approach in education. Author's version. M.: Research Center of the quality of specialists' training.

Zvonnikova, V., \& Chelyshkova, M. (2009). Modern means of evaluating of learning outcomes. M.: ACADEMY.

\section{Copyrights}

Copyright for this article is retained by the author(s), with first publication rights granted to the journal.

This is an open-access article distributed under the terms and conditions of the Creative Commons Attribution license (http://creativecommons.org/licenses/by/3.0/). 